\title{
Nota de la Penitenciaría Apostólica sobre la importancia del foro interno y la inviolabilidad del sigilo sacramental (29 junio 2019)*
}

«El Hijo de Dios con su encarnación se ha unido, en cierto modo, con todo hombre» ${ }^{1}$; con sus gestos y sus palabras iluminó su dignidad más elevada e inviolable; en sí mismo, muerto y resucitado, restauró a la humanidad caída, superando las tinieblas del pecado y de la muerte; a todos los que creen en él, abrió la relación con su Padre; con la efusión del Espíritu Santo, consagró la Iglesia, comunidad de creyentes, como su verdadero cuerpo y compartió en ella su propio poder profético, real y sacerdotal, para que fuera en el mundo como prolongación de su propia presencia y misión, proclamando la verdad a los hombres de todas las épocas, guiándolos al esplendor de su luz, permitiendo que sus vidas fueran verdaderamente tocadas y transfiguradas.

En este tiempo de la historia humana tan turbulento, el creciente progreso tecnocientífico no parece corresponder a un adecuado desarrollo ético y social, sino más bien a una verdadera y propia «involución» cultural y moral que, olvida a Dios -incluso cuando no hostil-, se vuelve incapaz de reconocer y respetar, en todas las esferas y a todos los niveles, las coordenadas esenciales de la existencia humana y, con ellas, de la vida misma de la Iglesia.

«Si el progreso técnico no se corresponde con un progreso en la formación ética del hombre, con el crecimiento del hombre interior [...] no es un progreso sino una amenaza para el hombre y para el mundo» ${ }^{2}$. Incluso en el campo de la comunicación privada y de los medios de co-

* Texto tomado de www.vatican.va.

1 Concilio Ecuménico VATiCANo II, Constitución pastoral sobre la Iglesia en el mundo actual Gaudium et spes, 7 de diciembre de 1965, n. 22.

2 Benedicto XVI, Carta Encíclica Spe salvi, 30 noviembre 2007, n. 22. 
municación, las «posibilidades técnicas» crecen desproporcionadamente, pero no el amor por la verdad, el compromiso con su búsqueda, el sentido de la responsabilidad ante Dios y ante los hombres; está surgiendo una preocupante desproporción entre los medios y la ética. La hipertrofia comunicativa parece volverse contra la verdad y, en consecuencia, contra Dios y contra el hombre; contra Jesucristo, Dios hecho hombre, y contra la Iglesia, su presencia histórica y real.

En las últimas décadas se ha extendido cierto «afán» por la información, casi independientemente de su fiabilidad y oportunidad reales, hasta el punto de que el «mundo de la comunicación» parece querer «sustituir» a la realidad, tanto condicionando su percepción como manipulando su comprensión. Desgraciadamente, la propia estructura eclesial, que vive en el mundo y a veces asume sus criterios, no es inmune a esta tendencia, que puede asumir los rasgos inquietantes de esta morbosidad. Incluso entre los creyentes, con frecuencia se emplean energías valiosas en la búsqueda de «noticias»-o de verdaderos «escándalos»- adecuadas para la sensibilidad de ciertas opiniones públicas, con fines y objetivos que ciertamente no pertenecen a la naturaleza teándrica de la Iglesia. Todo esto en grave detrimento del anuncio del Evangelio a toda criatura y de las necesidades de la misión. Hay que reconocer humildemente que a veces ni siquiera las filas del clero, hasta las más altas jerarquías, están exentas de esta tendencia.

En efecto, invocando como último tribunal el juicio de la opinión pública, con demasiada frecuencia se da a conocer información de todo tipo, incluso de las esferas más privadas y confidenciales, que afectan inevitablemente a la vida eclesial, inducen $-\mathrm{O}$ al menos favorecen- juicios temerarios, dañan ilícita e irreparablemente la buena fama de los demás, así como el derecho de toda persona a defender su intimidad (cfr. c. 220 CIC). Las palabras de san Pablo a los Gálatas suenan, en este escenario, particularmente relevantes: «Porque hermanos, habéis sido llamados a la libertad; solo que no toméis de esa libertad pretexto para la carne; antes, al contrario, servíos por amor los unos a los otros. [...] Pero si os mordéis y os devoráis mutuamente ¡mirad no vayáis mutuamente a destruiros!» (Gálatas 5,13-15).

En este contexto, un cierto «prejuicio negativo» preocupante parece afirmarse contra la Iglesia católica, cuya existencia se presenta cul- 
turalmente y se reinterpreta socialmente, por una parte, a la luz de las tensiones que pueden producirse dentro de la misma jerarquía y, por otra, a partir de los recientes escándalos de abusos, terriblemente perpetrados por algunos miembros del clero. Este prejuicio, olvidando la verdadera naturaleza de la Iglesia, su auténtica historia y el impacto real y beneficioso que siempre ha tenido y tiene en la vida de los hombres, se traduce a veces en la injustificable «reivindicación» de que la propia Iglesia, en ciertos asuntos, viene a conformar su propio sistema jurídico a las órdenes civiles de los Estados en los que vive, como la única posible «garantía de corrección y rectitud».

Ante todo esto, la Penitenciaría Apostólica ha considerado oportuno intervenir, con esta Nota, para reafirmar la importancia y favorecer una mejor comprensión de aquellos conceptos, propios de la comunicación eclesial y social, que hoy parecen haberse vuelto más ajenos a la opinión pública y, a veces, a los mismos ordenamientos jurídicos civiles: el sigilo sacramental, la confidencialidad innata del foro extra-sacramental interno, el secreto profesional, los criterios y límites propios de cualquier otra comunicación.

\section{Sigilo SACRAMENTAL}

Recientemente, hablando del sacramento de la Reconciliación, el Santo Padre Francisco quiso reafirmar la indispensabilidad e indisponibilidad del sigilo sacramental: «La Reconciliación, en sí misma, es un bien que la sabiduría de la Iglesia ha salvaguardado siempre con toda su fuerza moral y jurídica con el sello sacramental. Aunque este hecho no sea siempre entendido por la mentalidad moderna, es indispensable para la santidad del sacramento y para la libertad de conciencia del penitente, que debe estar seguro, en cualquier momento, de que el coloquio sacramental permanecerá en el secreto del confesionario, entre su conciencia que se abre a la gracia y Dios, con la mediación necesaria del sacerdote. El sello sacramental es indispensable y ningún poder humano tiene jurisdicción, ni puede reclamarla, sobre él» ${ }^{3}$.

3 Francisco, Discurso a los participantes del xxx Curso sobre el Foro Interno organizado por la Penitenciaría Apostólica, 29 de marzo de 2019. 
El secreto inviolable de la Confesión proviene directamente de la ley divina revelada y está arraigado en la naturaleza misma del sacramento, hasta el punto de no admitir excepción alguna en el ámbito eclesial ni, menos aún, en el ámbito civil. En la celebración del sacramento de la Reconciliación, en efecto, se encierra la esencia misma del cristianismo y de la Iglesia: el Hijo de Dios se hizo hombre para salvarnos y decidió implicar, como «instrumento necesario» en esta obra de salvación, a la Iglesia y, en ella, a aquellos que él eligió, llamó y constituyó como sus ministros.

Para expresar esta verdad, la Iglesia siempre ha enseñado que los sacerdotes, en la celebración de los sacramentos, actúan «in persona Christi capitis», es decir, en la persona misma de Cristo cabeza: «Cristo nos permite usar su "yo", hablamos en el "yo" de Cristo, Cristo nos "atrae a sí" y nos permite unirnos, nos une a su "yo". [...] esta unión con su "yo" es la que se realiza en las palabras de la consagración. También en el "yo te absuelvo" -porque ninguno de nosotros podría absolver de los pecados- es el "yo" de Cristo, de Dios, el único que puede absolver» ${ }^{4}$.

Todo penitente que se dirige humildemente al sacerdote para confesar sus pecados da testimonio del gran misterio de la Encarnación y de la esencia sobrenatural de la Iglesia y del sacerdocio ministerial, a través del cual Cristo resucitado viene al encuentro de los hombres, toca sacramentalmente -es decir, realmente- su vida y los salva. Por eso, la defensa del sigilo sacramental por parte del confesor, si es necesario usque ad sanguinis efusionem, representa no solo un acto de «lealtad»debida al penitente, sino mucho más: un testimonio necesario -un «martirio»- dado directamente a la unicidad y universalidad salvífica de Cristo y de la Iglesia ${ }^{5}$.

La materia del sigilo está actualmente expuesta y regulada por los cánones 983-984 y $1388 \$ 1$ del CIC y por el c. 1456 del CCEO, así como por el n. 1467 del Catecismo de la Iglesia Católica, donde se lee significativamente no que la Iglesia «establece» en virtud de su autoridad, sino que «declara»-es decir, reconoce como un hecho irreducti-

4 Benedicto XVI, Coloquio con los sacerdotes, 10 de junio de 2010.

5 Cfr. Congregación Para la Doctrina De la Fe, Declaración Dominus Iesus sobre la unicidad y la universalidad salvífica de fesucristo y de la Iglesia, 6 de agosto de 2000. 
ble, que deriva precisamente de la santidad del sacramento instituido por Cristo- «todo sacerdote que oye confesiones está obligado a guardar un secreto absoluto sobre los pecados que sus penitentes le han confesado, bajo penas muy severas». El confesor nunca y por ninguna razón puede «descubrir al penitente, de palabra o de cualquier otro modo, y por ningún motivo» (canon $983 \$ 1 \mathrm{CIC}$ ), así como «está terminantemente prohibido al confesor hacer uso, con perjuicio del penitente, de los conocimientos adquiridos en la confesión, aunque no haya peligro alguno de revelación» (canon $984 \$ 1$ CIC).

La doctrina ha contribuido también a precisar el contenido del sigilo sacramental, que incluye «todos los pecados del penitente y de los demás conocidos por la confesión del penitente, mortales y veniales, ocultos y públicos, en cuanto se manifiestan en relación con la absolución y, por tanto, conocidos por el confesor en virtud de la ciencia sacramental» ${ }^{6}$. El sigilo sacramental, por tanto, concierne a todo lo que el penitente ha acusado, también en el caso de que el confesor no conceda la absolución; si la confesión es inválida o por alguna razón no se da la absolución, sin embargo, el sigilo debe mantenerse.

El sacerdote, de hecho, se entera de los pecados del penitente «no ut homo, sed ut Deus - no como hombre, sino como Dios-» ${ }^{7}$, hasta el punto de que simplemente «no sabe» lo que se le ha dicho en sede de confesión, porque no lo ha escuchado como hombre, sino, precisamente, en nombre de Dios. El confesor podría, por tanto, también «jurar», sin perjuicio de su propia conciencia, que «no sabe» lo que solo sabe como ministro de Dios. Por su naturaleza peculiar, el sigilo sacramental vincula incluso al confesor «interiormente», hasta el punto de que se le prohíbe recordar la confesión voluntariamente y se le exige que suprima cualquier recuerdo involuntario de la misma. Al secreto que se deriva del sigilo está también obligado quien, de cualquier modo, ha llegado a conocer los pecados de confesión: «También están obligados a guardar secreto el intérprete, si lo hay, y todos aquellos que, de cualquier manera, hubieran tenido conocimiento de los pecados por la confesión» (c. $983 \$ 2 \mathrm{CIC})$.

6 V. De Paolis - D. Cito, Le sanzioni nella Chiesa. Comentario al Código de Derecho Canónico, Libro VI, Urbaniana University Press, Ciudad del Vaticano 2000, 345.

7 Tomás de Aquino, Summa Theologiae, Supl. 11, 1, ad 2. 
La prohibición absoluta impuesta por el sigilo sacramental es tal que impide al sacerdote hablar del contenido de la confesión con el penitente mismo, fuera del sacramento, «salvo explícito, y tanto mejor si no es necesario, consentimiento del penitente ${ }^{8}$. Por lo tanto, el sigilo va también más allá de la disponibilidad del penitente, que, una vez celebrado el sacramento, no tiene el poder de eximir al confesor de la obligación del secreto, porque este deber viene directamente de Dios.

La defensa del sigilo sacramental y la santidad de la confesión no pueden constituir nunca alguna forma de connivencia con el mal, al contrario, representan el único antídoto verdadero contra el mal que amenaza al hombre y al mundo entero; son la posibilidad real de abandonarse al amor de Dios, de dejarse convertir y transformar por este amor, aprendiendo a corresponderlo concretamente en la propia vida. En presencia de pecados que constituyen algún tipo de delito, nunca está consentido imponer al penitente, como condición para la absolución, la obligación de entregarse a la justicia civil, en virtud del principio natural, aplicado en todos los sistemas, según el cual «nemo tenetur se detegere». $\mathrm{Al}$ mismo tiempo, sin embargo, pertenece a la misma «estructura» del sacramento de la Reconciliación, como condición para su validez, el arrepentimiento sincero, junto con la firme intención de enmendar y no repetir el mal cometido. Si está presente un penitente que ha sido víctima del mal ajeno, el confesor tiene el deber de instruirlo sobre sus derechos, así como sobre los instrumentos jurídicos concretos que deben utilizarse para denunciar el hecho en el foro civil y/o eclesiástico y acogerse a la justicia.

Cualquier acción política o iniciativa legislativa encaminada a «forzar» la inviolabilidad del sigilo sacramental constituiría un delito inaceptable contra las libertas Ecclesiae, que no reciben la legitimidad de los Estados individuales, sino de Dios; también constituiría una violación de la libertad religiosa, que es jurídicamente fundamental para cualquier otra libertad, incluida la libertad de conciencia de los ciudadanos individuales, ya sean penitentes o confesores. Violar el sigilo equivaldría a violar al pobre hombre que hay en el pecador. 8 JUAN PABLO II, Discurso a los miembros de la penitenciaría apostólica y a los padres peniten-
cieros de las basilicas romanas, 12 de marzo de 1994. 


\section{FORO INTERNO EXTRA-SACRAMENTAL Y DIRECCIÓN ESPIRITUAL}

El llamado «foro interno extra-sacramental» pertenece también a la esfera jurídico-moral del foro interno, siempre oculto, pero externo al sacramento de la Penitencia. También en esto la Iglesia ejerce su propia misión y poder salvífico: no perdonar los pecados, sino conceder gracias, romper los lazos legales (como la censura) y ocuparse de todo lo que concierne a la santificación de las almas y, por tanto, de la esfera propia, íntima y personal de cada creyente.

La dirección espiritual pertenece de modo particular al foro interno extra-sacramental, en el que el creyente confía su propio camino de conversión y santificación a un sacerdote, a un consagrado o a un laico determinado.

El sacerdote ejerce este ministerio en virtud de su misión de representar a Cristo, conferida por el sacramento del orden y que debe ejercerse en la comunión jerárquica de la Iglesia, a través de los llamados tria munera: la tarea de enseñar, de santificar y de gobernar. Los laicos, en virtud de su sacerdocio bautismal y del don del Espíritu Santo.

En la dirección espiritual, los fieles abren libremente el secreto de su conciencia al director/guía espiritual, para ser guiados y apoyados en la escucha y cumplimiento de la voluntad de Dios.

Por tanto, también este ámbito particular exige un cierto grado de secreto ad extra, inherente al contenido de los discursos espirituales y que deriva del derecho de cada uno al respeto de su propia intimidad (cfr. c. 220 CIC). Aunque solo de modo «análogo» a lo que sucede en el sacramento de la confesión, el director espiritual llega a conocer la conciencia de los fieles individuales en virtud de su relación «especial» con Cristo, que deriva de su santidad de vida y -si es un clérigo- de la propia Orden sagrada recibida.

Como testimonio de la especial confidencialidad concedida a la dirección espiritual, se debe considerar la prohibición, aprobada por el derecho, de pedir no solo la opinión del confesor, sino también la del director espiritual, con ocasión de la admisión a las Santas Ordenes o, viceversa, para la salida del seminario de los candidatos al sacerdocio (cfr. c. $240 \$ 2$ CIC; c. $339 \$ 2$ CCEO). De la misma manera, la Instrucción Sanctorum Mater de 2007, relativa a la realización de investigaciones diocesanas o eparquiales sobre las Causas de los Santos, pro- 
híbe la admisión no solo de los confesores para dar testimonio de la protección del sigilo sacramental, sino también de los mismos directores espirituales del Siervo de Dios, también por todo lo que han sabido en el foro de conciencia, fuera de la confesión sacramental ${ }^{9}$.

Esta necesaria confidencialidad será tanto más «natural» para el director espiritual cuanto más aprenda a reconocer y a «conmoverse» por el misterio de la libertad de los fieles que, a través de él, se dirigen a Cristo; el director espiritual debe concebir su propia misión y su propia vida exclusivamente ante Dios, al servicio de su gloria, para el bien de la persona, de la Iglesia y para la salvación del mundo entero.

\section{Secretos y Otros LÍMITES PROPIOS DE LA COMUNICACióN}

De naturaleza distinta a la del ámbito del foro interno, sacramental y extra-sacramental, son las confidencias hechas bajo el sigilo del secreto, así como de los llamados «secretos profesionales», que están en posesión de determinadas categorías de personas, tanto en la sociedad civil como en la estructura eclesial, en virtud de un oficio especial que desempeñan para las personas o para la comunidad.

Estos secretos, en virtud de la ley natural, deben ser guardados siempre, «salvo -dice el Catecismo de la Iglesia Católica en el n. 2491salvo los casos excepcionales en los que el no revelarlos podría causar al que los ha confiado, al que los ha recibido o a un tercero daños muy graves y evitables únicamente mediante la divulgación de la verdad».

Un caso particular de secreto es el del «secreto pontificio», que vincula en virtud del juramento relacionado con el ejercicio de ciertos oficios al servicio de la Sede Apostólica. Si el juramento de secreto siempre vincula coram Deo que lo hizo, el juramento relacionado con el «secreto papal» tiene como razón última el bien público de la Iglesia y la salus animarum. Presupone que este bien y las propias exigencias de la salus animarum, incluido, por tanto, el uso de informaciones que no están bajo sigilo, pueden y deben ser correctamente interpretadas solo por la Sede Apostólica, en la persona del Romano Pontífice, a quien

9 Congregación Para las CaUSAS De los SANTOS, Sanctorum Mater, Instrucción para la realización de investigaciones diocesanas o eparquiales sobre las causas de los santos, 17 de mayo de 2007, art. $101 \$ 2$. 
Cristo el Señor constituyó y puso como principio y fundamento visible de la unidad de la fe y de la comunión de toda la Iglesia ${ }^{10}$.

En cuanto a los demás ámbitos de la comunicación, tanto pública como privada, en todas sus formas y expresiones, la sabiduría de la Iglesia ha indicado siempre como criterio fundamental la «regla dorada», pronunciada por el Señor y expresada en el Evangelio de Lucas: «Y lo que queráis que os hagan los hombres, hacédselo vosotros igualmente» (Lucas 6,31). De este modo, tanto en la comunicación de la verdad como en el silencio sobre ella, cuando los que la piden no tienen derecho a conocerla, es siempre necesario conformar su vida al precepto del amor fraterno, teniendo ante sus ojos el bien y la seguridad del prójimo, el respeto de la vida privada y al bien común ${ }^{11}$.

Como deber particular de comunicar la verdad, dictada por la caridad fraterna, no se puede dejar de mencionar la «corrección fraterna», en sus diversos grados, enseñada por el Señor. Sigue siendo el horizonte de referencia, cuando sea necesario y según lo que las circunstancias concretas permitan y exijan: $\ll$ Si tu hermano llega a pecar, vete y repréndele, a solas tú con él. Si te escucha, habrás ganado a tu hermano. Si no te escucha, toma todavía contigo uno o dos, para que todo asunto quede zanjado por la palabra de dos o tres testigos. Si les desoye a ellos, díselo a la comunidad» (Mateo 18,15-17).

En un tiempo de comunicación masiva, en el que toda la información se «quema» y con ella, desgraciadamente, también parte de la vida de las personas, es necesario volver a aprender el poder de la palabra, su poder constructivo, pero también su potencial destructivo; debemos asegurarnos de que el sigilo sacramental nunca sea violado por nadie y de que la necesaria reserva relacionada con el ejercicio del ministerio eclesial sea siempre celosamente guardada, teniendo como único horizonte la verdad y el bien integral de la gente.

Invoquemos del Espíritu Santo, para toda la Iglesia, un ardiente amor a la verdad en todos los ámbitos y circunstancias de la vida; la capacidad de conservarla plenamente en el anuncio del Evangelio a toda criatura, la disponibilidad al martirio para defender la inviolabilidad del

10 Cfr. Concilio Ecuménico Vaticano II, Constitución dogmática sobre la Iglesia Lumen Gentium, 21 de noviembre de 1964, n. 18.

11 Cfr. Catecismo de la Iglesia Católica, n. 2489. 
sigilo sacramental, así como la prudencia y la sabiduría necesarias para evitar cualquier uso instrumental y erróneo de esa información propia de la vida privada, social y eclesial, que puede volverse ofensiva de la dignidad de la persona y de la misma Verdad, que es siempre Cristo, Señor y Cabeza de la Iglesia.

En la celosa custodia del sigilo sacramental y de la necesaria discreción ligada al foro extra-sacramental interno y a otros actos de ministerio, resplandece una síntesis particular entre las dimensiones petrina y mariana en la Iglesia.

Con Pedro, la esposa de Cristo conserva, hasta el final de la historia, el ministerio institucional del «poder de las llaves»; como María Santísima, la Iglesia conserva «todas las cosas en su corazón» (Lucas $2,51 \mathrm{~b}$ ), sabiendo que en ellas se refleja esa luz que ilumina a todo hombre y que, en el espacio sagrado entre la conciencia personal y Dios, debe ser preservada, defendida y custodiada.

El Sumo Pontífice Francisco, en fecha 21 de junio de 2019, aprobó esta Nota y ordenó su publicación.

Dado en Roma, desde la sede de la Penitenciaría Apostólica, el 29 de junio, año del Señor 2019, en la solemnidad de los santos Pedro y Pablo, Apóstoles.

Mauro Card. Piacenza

Penitenciario Mayor

Mons. Krzysztof Nykiel

Regente 